\title{
Diagnostic value of CSF protein profile in a Portuguese population of SCJD patients
}

\author{
Inês Esteves Baldeiras • Maria Helena Ribeiro • \\ Paula Pacheco · Álvaro Machado · Isabel Santana • \\ Luís Cunha $\cdot$ Catarina Resende Oliveira
}

Received: 25 March 2009/Revised: 22 April 2009/Accepted: 22 April 2009/Published online: 6 May 2009

(c) Springer-Verlag 2009

\begin{abstract}
The clinical diagnosis of sporadic CreutzfeldtJakob disease (sCJD) is difficult, and reliable markers are highly desired. In this work we assess the value of several cerebrospinal fluid (CSF) markers for sCJD diagnosis. Within the framework of the Portuguese Epidemiological Surveillance Program for Human Prion Diseases, CSF samples from 71 patients with clinically suspected SCJD, 30 definite sCJD and 41 non-CJD patients, were analysed for the presence of 14-3-3 protein. CSF levels of tau (t-tau), and phosphorylated tau (p-tau181), S-100b and $\beta$ amyloid (A $\beta 42)$ proteins were determined. The influence of clinical and genetic characteristics on CSF markers sensitivity was also evaluated. Protein 14-3-3 was detected in 29/30 sCJD patients and 9/41 non-CJD patients. Extremely elevated
\end{abstract}

I. E. Baldeiras $(\varangle) \cdot$ M. H. Ribeiro · C. R. Oliveira

Laboratory of Neurochemistry, Neurology Department,

Coimbra University Hospital, Praceta Mota Pinto,

3000 Coimbra, Portugal

e-mail: ines.baldeiras@sapo.pt

I. E. Baldeiras - M. H. Ribeiro - I. Santana - L. Cunha

C. R. Oliveira

Faculty of Medicine, Center for Neuroscience and Cell Biology,

University of Coimbra, 3004-504 Coimbra, Portugal

P. Pacheco

Genetics Department,

National Institute of Health Dr. Ricardo Jorge,

Av Padre Cruz, 1649-016 Lisbon, Portugal

Á. Machado

Neurology Department, Hospital S. Marcos,

Largo Carlos Amarante Ap. 2242,

4701-965 Braga, Portugal

I. Santana - L. Cunha

Neurology Department, Coimbra University Hospital,

Praceta Mota Pinto, 3000 Coimbra, Portugal t-tau and S-100b protein levels were found in SCJD patients, while p-tau181 levels were only slightly elevated and $\mathrm{A} \beta 42$ showed no differences compared to controls. 14-3-3 was the most sensitive parameter (97\%), but its specificity was low (78\%); sensitivity/specificity for other proteins were: S-100b-93/93\%, t-tau-93/95\%, with maximum accuracy being obtained by a combination of tests (14-3-3 combined with either t-tau or S-100b, or combining S-100b with $\mathrm{t}$-tau/A $\beta 42$ or $\mathrm{p}$-tau/t-tau ratios). The sensitivity of 14-3-3, as well as of p-tau181/t-tau ratio, was decreased in younger patients with long disease duration, with the PrP-2 isotype and MV genotype. Both 14-3-3, t-tau and S-100b are sensitive markers for SCJD, but 14-3-3 specificity seems to be lower in this special clinical setting of rapidly progressing dementias. We propose that in cases with a 14-3-3 weak positive result, or in young patients with long disease duration, a second CSF marker would be valuable for the diagnosis of SCJD.

Keywords 14-3-3 Protein - Cerebrospinal fluid . Creutzfeldt-Jakob disease $\cdot$ Protein markers .

$P R N P$ genotype

\section{Introduction}

Sporadic Creutzfeldt-Jakob disease (sCJD) is the most common human prion disease. It causes a rapidly progressive neurodegeneration, ultimately leading to the patient's death within months to few years [27]. To date, a definite diagnosis can only be made by neuropathological examination of brain tissue with immunochemical demonstration of the pathogenic isoform of the prion protein $\left(\mathrm{PrP}^{\mathrm{Sc}}\right)$ [4]. Clinically, the diagnosis of possible SCJD is made based on neurological findings of rapidly 
progressive dementia (less than 2 years duration) together with at least two of the following symptoms: myoclonus, ataxia, pyramidal or extrapyramidal signs, akinetic mutism, visual and psychiatric disturbances [26]. The heterogeneity of the symptoms, especially early in the course of the disease, may resemble other neurodegenerative disorders, reinforcing the need for reliable intra vitam diagnostic markers. Therefore, the probable diagnosis of SCJD is based, not only on the clinical features and course of the disease, but also on electroencephalography (EEG), magnetic resonance imaging (MRI) and cerebrospinal fluid (CSF) findings [41]. EEG records are considered typical when they fulfil validated criteria: sustained periodic sharp wave complexes (PSWC) lasting 100-600 ms, with a variability of $<500 \mathrm{~ms}$, demonstrating a bi- or tri-phasic morphology and seen in generalized or lateralized distribution [34]. Although, at present, cerebral MRI is not part of the diagnostic criteria for SCJD, high signal in the putamen and caudate nucleus when using long-repetition time pulse sequences are considered characteristic [8].

In recent years, CSF analysis has become increasingly important in the diagnosis of SCJD. Immunodetection of protein 14-3-3 in CSF was originally demonstrated to have a high sensitivity and specificity for SCJD $[19,42]$ and has, therefore, been included by the World Health Organization (WHO) in the diagnostic criteria for probable disease [41]. However, this view has been challenged by findings of poor specificity $[6,7]$ and low sensitivity in autopsy-proven SCJD cases [11]. One of the major limitations of this assay is that the 14-3-3 immunoblot is usually analysed in a qualitative manner, by visual inspection, leading to a subjective interpretation of borderline results. Moreover, its sensitivity is believed to be strongly influenced by disease duration $[9,30,39]$, and a number of other conditions that lead to neuronal injury are known to give false positive results. These include central nervous system infections, cerebrovascular diseases, encephalopathies, brain tumours, inflammatory conditions and other types of dementia.

In order to overcome some of these limitations, various other brain-derived proteins have been studied in the CSF, such as tau, phosphorylated tau, full length $\beta$-amyloid (A $\beta 42), \mathrm{S}-100 \mathrm{~b}$ and neuron-specific enolase (NSE) [36]. Following the principle that CSF proteins reflect changes in pathological brain conditions, elevated levels of these proteins are used as surrogate markers for neuronal damage (14-3-3, tau, NSE) or astrocytic gliosis (S-100b). CSF total tau (t-tau) reaches extremely high levels in SCJD, probably reflecting the extent of the neurodegenerative process, and has been reported to be clinically useful, with sensitivity and specificity for SCJD similar to the 14-3-3 test [17, 22, 38, 39]. Unlike what happens in Alzheimer's disease (AD), hyperphosphorylation of tau and formation of neurofibrillary tangles (NFTs) do not occur in sCJD. As so the ratio between phosphorylated tau (p-tau) and t-tau levels (p-tau/ $\mathrm{t}$-tau) was shown to improve discrimination between $\mathrm{AD}$ and SCJD, with lower levels in favour of the latter [5, 28, 32]. Reduced $\mathrm{A} \beta 42 \mathrm{CSF}$ levels have also been reported in sCJD patients, as in $\mathrm{AD}$, but mostly overlapping [17, 38, 39]. NSE and S-100b are elevated in SCJD patients, but do not seem to attain sufficient sensitivity and specificity for differential diagnosis [21, 30, 43].

Most studies compared sCJD patients with either a group of patients with a defined neurological condition (mainly AD or fronto-temporal dementia) or with a control group of individuals without dementia. In a clinical setting, putative CSF markers would be most useful in identifying SCJD cases in a cohort of mixed pathologies with a similar presentation of rapidly progressive dementia and therefore suspected to have SCJD. A few studies have addressed this problem [2, 12, 39] with some limitations, either enrolling a very limited number of patients, or assessing only two or three different CSF markers.

In this study, conducted in the framework of the Portuguese Epidemiological Surveillance Program for Human Prion Diseases, we evaluated the utility of several CSF protein markers (14-3-3 protein, t-tau, p-tau, A $\beta 42$ and S-100b) in a population of patients with suspected SCJD. We also analysed the influence of patients clinical and genetic characteristics on the sensitivity/specificity of the CSF markers.

\section{Methods}

\section{Sample characterization}

Samples from patients with a clinical suspicion of CJD were collected as part of their routine clinical diagnosis investigation and sent to our laboratory for the detection of 14-3-3 protein in CSF. Herein we report the results form the patients for which a confirmatory diagnosis was available: 30 neuropathologically confirmed sporadic CJD (sCJD), and 41 patients proved to have an alternative diagnosis (non-CJD).

The diagnosis of definite SCJD was made according to standard, international agreed criteria [41], including postmortem neuropathological confirmation (29/30) or brain biopsy. In the non-CJD group the appropriate diagnosis criteria were used. This group included patients with the following: Alzheimer's disease (6), fronto-temporal dementia (5), Lewy body dementia (6), vascular dementia (5), reversible encephalopathy (5), acute psychosis (4), Parkinson's disease and other movement disorders (5), neoplastic syndromes (4) and Whipple's disease (1). These diagnoses were established by histology or according to clinical evolution. The study was performed in accordance with the ethical standards laid down in the 1964 Declaration of Helsinki. 
CSF proteins evaluation: $14-3-3, \mathrm{~A} \beta 42$, t-tau, $\mathrm{p}$-tau and S-100b

CSF samples, collected in sterile polypropylene tubes, were centrifuged at 2,500 $\mathrm{rpm}$ for $5 \mathrm{~min}$, aliquoted and stored at $-80^{\circ} \mathrm{C}$ until analysis. Immunodetection of protein $14-3-3$ in CSF was done as described previously [42], with minor modifications. Briefly, CSF proteins were separated by sodium dodecyl sulphate-polyacrylamide gel electrophoresis and detection was carried out by incubation with mouse anti-14-3-3 beta monoclonal antibody (sc-1657, Santa Cruz Biotechnology, USA) followed by horseradish peroxidaseconjugated anti-mouse immunoglobulin (DakoCytomation, Denmark). Membranes were developed by enhanced chemiluminescence (SuperSignal, West Pico, PIERCE, USA). A positive and a weak positive control (CSF from patients with histopathologically confirmed sporadic CJD with a strong or a weak protein 14-3-3 signal, respectively), a negative control (CSF from a patient without histological evidence of CJD and showing no protein 14-3-3 signal) and molecular weight markers were included in the run. All samples were tested twice and the result evaluated by three independent observers. In cases of contradictory results or when an agreement between the observers could not be reached, a third test was made to establish a final result.

CSF A $\beta 42$, t-tau and p-tau-181 were measured by commercially available sandwich ELISA kits (Innotest, Innogenetics, Ghent, Belgium), according to the manufacturer instructions, as previously reported [12, 17] CSF S-100b was measured by a commercially ELISA kit (Sangtec 100 ELISA, DiaSorin, Stillwater, MN, USA), according to the manufacturer instructions. All assays were performed sequentially in a clinical routine setting.

PrP-isotypes determination

In 16 of the 30 definite sCJD cases, autopsy or biopsy tissue was sent to the laboratory for $\operatorname{PrP}$ western blot isotyping. For this purpose, brain tissue homogenates $(10 \%$ w/v) from cerebellum, frontal, occipital and temporal cortex (when available), were prepared from frozen samples and digested with proteinase $\mathrm{K}$ (Roche Diagnostics $\mathrm{GmbH}$, Mannheim, Germany). Samples were then analysed by western blotting as previously described [16]. Molecular weight markers and proteinase K-digested brain extracts of histopathologically confirmed sCJD cases were included in each run. Detection was made using first antiPrP monoclonal antibody and then horseradish peroxidaseconjugated anti-mouse immunoglobulin and streptavidin peroxidase (all from DakoCytomation, Denmark). The membranes were developed using chemiluminescent substrate (SuperSignal, West Pico, Pierce Biotechnology, Rockford, USA).
ApoE and PRNP genotyping

A subset of patients was genotyped for ApoE (25 sCJD and 29 non-CJD) and PRNP genes (28 sCJD). Blood samples were collected into EDTA tubes and DNA was isolated from whole blood using a commercial kit (Roche Diagnostics $\mathrm{GmbH}$, Manheim, Germany), as described by the manufacturer.

ApoE genotype was determined by polymerase chain reaction-restriction fragment length polymorphisms (PCRRFLP) assay, as previously described [10].

The open reading frame (ORF) of PRNP gene was amplified by PCR using the following primers: forwardPr-85/-62 5'-GCT ATG CAC TCA TTC ATT ATG CAG$3^{\prime}$ and reverse-Pr $+79 /+57$ 5'-CTA AAA GGG CTG CAG GTG GAT AC- $3^{\prime}$. DNA sequencing of the amplified product was done using the ABI PRISM ${ }^{\mathrm{TM}}$ Dye Terminator Cycle Sequencing System (Perkin-Elmer, Norwalk, CA). The obtained sequence was compared with the PRNP sequence deposited in GeneBank M13899 (http://www. ncbi.nlm.nih.gov/Genbank).

\section{Statistical analysis}

Statistical analysis was performed using the program SPSS 13.0. The Kolmogorov-Smirnov test showed that the results obtained with t-tau, $\mathrm{p}$-tau and $\mathrm{S}-100 \mathrm{~b}$ did not have a normal distribution, therefore the Mann-Whitney $U$ test was used for comparing these variables between diagnostic groups and within groups. For continuous variables showing a normal distribution (age, duration of disease and A $\beta 42$ ), the Student's $t$ test was used. For comparison of quantitative parameters between different ApoE genotypes, either one-ANOVA followed by the Bonferroni post-test or the non-parametric Kruskal-Wallis test were used. $\chi^{2}$ test was used to assess differences between categorical variables and to test differences in sensitivity between CSF markers. Receiver operating characteristics (ROC) curve analysis was used to define the sensitivity, specificity and optimal cut off values of the different markers. Spearman's test was used for correlation between parameters. Data in the text are presented as mean \pm standard error of means (SEM).

\section{Results}

Clinical and molecular characterization of the patients

The principal features of all patients for whom a definite diagnosis was available are summarized in Table 1. There were no differences regarding gender or age between the sCJD and the non-CJD group, but disease duration was 
Table 1 Clinical features and principal investigation findings of all patients

\begin{tabular}{lll}
\hline & $\begin{array}{l}\text { sCJD } \\
(n=30)\end{array}$ & $\begin{array}{c}\text { Non-CJD } \\
(n=41)\end{array}$ \\
\hline Gender (M/F) & $13 / 17$ & $19 / 22$ \\
Age, years (min-max) & $68.3 \pm 1.7$ & $63.6 \pm 2.1$ \\
& $(47-84)$ & $(16-84)$ \\
Duration disease, months & $3.7 \pm 0.8^{* *}$ & $10.2 \pm 2.4$ \\
$\quad($ min-max) & $(1-21)$ & $(1-84)$ \\
ApoE genotype & $\varepsilon 2 \varepsilon 3-5$ & $\varepsilon 2 \varepsilon 3-4$ \\
& $\varepsilon 2 \varepsilon 4-0$ & $\varepsilon 2 \varepsilon 4-1$ \\
& $\varepsilon 3 \varepsilon 3-17$ & $\varepsilon 3 \varepsilon 3-12$ \\
& $\varepsilon 3 \varepsilon 4-3$ & $\varepsilon 3 \varepsilon 4-11$ \\
PRNP codon 129 genotype & $\varepsilon 4 \varepsilon 4-0$ & $\varepsilon 4 \varepsilon 4-1$ \\
& MM-18 & - \\
PrP isotype & MV-6 & \\
EEG-typical/total $(\%)$ & VV-4 & \\
MRI-characteristic/total $(\%)$ & $10 / 25(40)^{* *}$ & $1 / 19(5)$ \\
$14-3-3$ in CSF (Pos/Wp/Neg) & $26 / 3 / 1 * * *$ & $0 / 9 / 32$ \\
\hline
\end{tabular}

Data are expressed as mean \pm SEM

Pos Positive, $W p$ weak positive, $\mathrm{Neg}$ negative

** $P<0.005$ versus non-CJD; *** $P<0.0001$ versus non-CJD

Table 2 Prevalence of symptoms in SCJD and non-CJD patients

\begin{tabular}{lrl}
\hline & $\begin{array}{r}\text { sCJD, } \% \\
(n=30)\end{array}$ & $\begin{array}{l}\text { Non-CJD, \% } \\
(n=41)\end{array}$ \\
\hline Myoclonus & $77 * *$ & 42 \\
Ataxia & $77 * * *$ & 29 \\
Extrapyramidal and/or pyramidal signs & 60 & 54 \\
Akinetic mutism & $43^{*}$ & 17 \\
Visual problems & 23 & 12 \\
Psychiatric problems & 60 & 68
\end{tabular}

Data are expressed as percentage of total

$* \quad P<0.05$ versus non-CJD; ** $P<0.005$ versus non-CJD; $* * * P<0.0001$ versus non-CJD

significantly shorter in the sCJD group. We also assessed the prevalence of symptoms in definite SCJD and non-CJD patients at the time of lumbar puncture (Table 2). Dementia was present in all patients, and at least one other symptom was present in all but four patients (non-CJD group). Myoclonus, ataxia, akinetic mutism or severe psychomotor slowing and inhibition were significantly more common in the sCJD group. Extrapyramidal or pyramidal signs and psychiatric problems were equally found in both groups. Visual problems were the least common of symptoms, showing also no difference between SCJD and non-CJD patients. Results regarding the principal diagnostic tests performed in SCJD suspected cases (EEG, cerebral MRI and CSF 14-3-3 immunoassay) are also shown in Table 1. The number of positive EEGs in the sCJD group was statistically higher than the number of typical sCJD-EEG results in the non-CJD group, resulting in a sensitivity of $65 \%$ and a specificity of $86 \%$. Cerebral MRI showed a rather low sensitivity (40\%), but a very high specificity (95\%), with only one out of 19 non-CJD patients (a patient with Whipple's disease) presenting with increased signal intensity in the caudate nucleus head.

Concerning molecular characteristics, PRNP codon 129 genotyping was available in 28 sCJD patients and $\operatorname{PrP}$ isotyping was performed in 16 patients (see Table 1). PrP type-1 was the most common (81\%) and the frequency of the various $P R N P$ genotypes was as follows: $64 \% \mathrm{MM}$, $21 \% \mathrm{MV}$, and only $14 \% \mathrm{VV}$. Combining these two features, it was possible to determine the molecular subtypes of 15 sCJD patients (not shown): 7 MM1, 4 MV1, 1 MV2, 1 VV1 and 2 VV2. The distribution of the different ApoE genotypes was not statistically different between the diagnostic groups, although there were differences regarding the frequency of $\varepsilon 4$ alleles $(P<0.05)$. Only three out of $25 \mathrm{sCJD}$ patients carried one $\varepsilon 4$ allele for ApoE, whereas in the non-CJD group close to half of them (13 out of 29) had at least one $\varepsilon 4$ allele. Within the sCJD group, there was a trend for individuals with $\varepsilon 2 \varepsilon 3$ genotype to be older and with longer disease duration $(P>0.05$; not shown).

\section{CSF proteins profile}

From the three diagnostic tests, CSF 14-3-3 immunoassay was by far the most sensitive, with 29 out of 30 sCJD patients presenting with a positive result (both positive and weak positive signals considered). A weak 14-3-3 band was also observed in three patients with encephalopathies, two Lewy body dementia, one Alzheimer's disease, one fronto-temporal dementia, one vascular dementia and one paraneoplastic syndrome. Overall, 14-3-3 test showed a sensitivity of $97 \%$ and a specificity of $78 \%$. Only one sCJD patient had a negative 14-3-3 result. This patient is a young woman (age 47), with an isolated dementia evolving over a 2-year period, with no investigational feature, except for the MRI, suggestive of sCJD and molecular subtype MV2 (Á. Machado, personal communication). Final diagnosis was made following brain biopsy.

Cerebrospinal fluid concentrations of $\mathrm{A} \beta 42$, t-tau, $\mathrm{p}$-tau181, S-100b, and the t-tau/A $\beta 42$ and $\mathrm{p}$-tau181/t-tau ratio for both SCJD and non-CJD patients are shown in Fig. 1. No significant difference in mean CSF A $\beta 42$ concentration was seen between SCJD and control groups $(454.3 \pm 47.5$ vs. $490.1 \pm 39.6 \mathrm{pg} / \mathrm{mL} ; P>0.05$; Fig. $1 \mathrm{a})$. Unlikely, CSF t-tau (Fig. 1b) and S-100b levels (Fig. 1d) 
Fig. 1 Box plots of CSF (a) A $\beta 42$, (b) t-tau, (c) p-tau181, (d) $\mathrm{S}-100 \mathrm{~b}$, (e) t-tau/A $\beta 42$ ratio and (f) $\mathrm{p}$-tau181/t-tau $(\times 100)$ ratio in SCJD and non-CJD patients. Plots show 10, 25, 50, 75 and 90th percentiles and outliers. The dotted line represents the optimal cut-off between SCJD with non-CJD patients. $(* P<0.05$ vs. non-CJD; $* * * P<0.0001$ vs. non-CJD)

Fig. 2 Correlations between CSF levels of (a) t-tau and p-tau181, (b) t-tau and S-100b and (c) p-tau181 and S-100b in sCJD patients. The Spearman's correlation factor $(r)$ and the statistical significance of the for each case correlations $(P)$ are represented
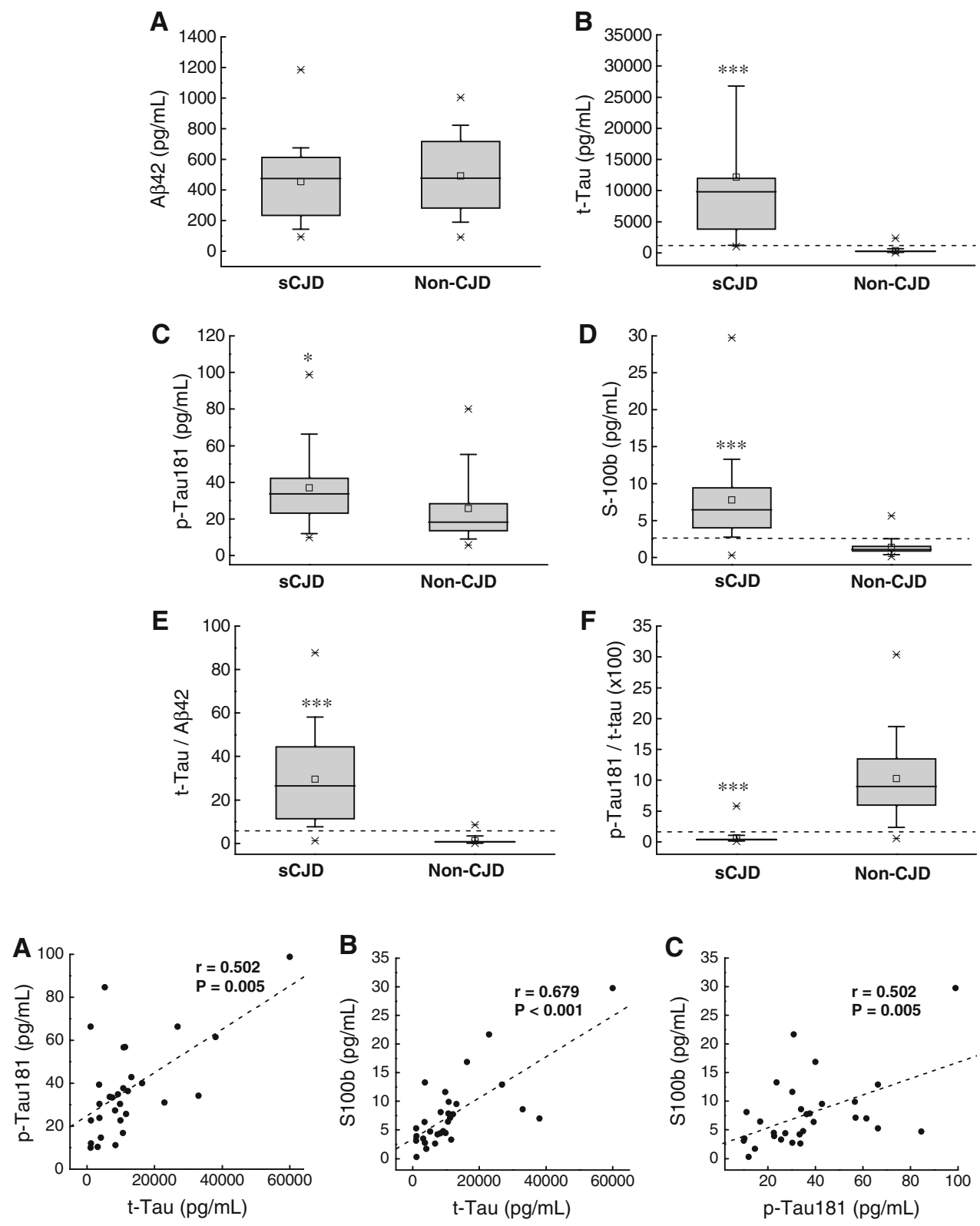

were markedly increased in sCJD patients (t-tau: 12 $186.9 \pm 2333.6$ vs. $385.7 \pm 67.7 \mathrm{pg} / \mathrm{mL} ; P<0.0001$; S-100b: $7.80 \pm 1.14$ vs. $1.39 \pm 0.17 \mathrm{pg} / \mathrm{mL} ; P<0.0001)$. However, this huge increase in t-tau CSF levels in SCJD patients was not accompanied by a similar change in p-tau181 levels, which were only slightly increased $(37.1 \pm 4.0$ vs. $25.7 \pm 2.9 \mathrm{pg} / \mathrm{mL} ; P<0.05 ;$ Fig. $1 \mathrm{c})$. These profiles of CSF t-tau and p-tau181 resulted in a strong increase in the $\mathrm{t}$-tau/A $\beta 42$ ratio $(29.6 \pm 4.0$ vs. $1.3 \pm 0.3$; $P<0.0001$; Fig. 1e) and a marked decrease in the p-tau181/ t-tau ratio in the SCJD group $(0.67 \pm 0.19$ vs. $10.30 \pm 1.03$; $P<0.0001$; Fig. 1f). In the sCJD group, but not in the nonCJD group, positive correlations between t-tau, p-tau181 and S-100b CSF levels were observed (Fig. 2).
Table 3 shows the sensitivity and specificity levels, derived from ROC curve analysis, of the assessed protein markers. $\mathrm{A} \beta 42$ and p-tau181 were excluded from this analysis, as their diagnostic accuracy between SCJD and non-CJD was shown to be very low (AUC $<0.700$ for both cases). For both t-tau and S-100b, we found an increased specificity, although a slightly lower sensitivity as compared with the 14-3-3 immunoblot. Discriminative power between SCJD and non-CJD was highest for $\mathrm{t}$-tau/A $\beta 42$ and p-tau181/t-tau ratios, correctly allocating $94 \%$ of the cases (67 out of 71). S-100b and t-tau alone correctly diagnosed 66 cases (93\%), while 14-3-3 immunoassay, although being the most sensitive test, presented the lowest number of correctly allocated cases $(86 \% ; 61$ out of 71$)$. 
Table 3 Sensitivity and specificity of the different protein markers tested for sCJD patients

\begin{tabular}{llll}
\hline Marker (cut-off value) & $\begin{array}{l}\text { Sensitivity } \\
(\%)\end{array}$ & $\begin{array}{l}\text { Specificity } \\
(\%)\end{array}$ & $\begin{array}{l}\text { AUC } \\
(95 \% \mathrm{CI})\end{array}$ \\
\hline 14-3-3 Protein (all bands) & 97 & 78 & - \\
t-tau $(>1,203 \mathrm{pg} / \mathrm{mL})$ & 90 & 95 & $\begin{array}{l}0.989^{* * *} \\
(0.974,1.005)\end{array}$ \\
S100b $(>2.59 \mathrm{pg} / \mathrm{ml})$ & 93 & 93 & $\begin{array}{l}0.943^{* * *} \\
(0.879,1.007)\end{array}$ \\
& & & $0.985^{* * *}$ \\
t-tau/A $\beta 42(>5.83)$ & 93 & 98 & $\begin{array}{l}(0.963,1.006) \\
0.980 * * * \\
\text { p-tau181/t-tau } \times 100\end{array}$ \\
$(<1.66)$ & 93 & 95 & $(0.956,1.005)$ \\
\hline
\end{tabular}

$A U C$ area under the curve, determined by ROC analysis

*** $P<0.0001$

Combination of tests clearly resulted in improved accuracy. Association of protein 14-3-3 with any of the other protein markers improved specificity (from 78 to 95-98\%), and association with $\mathrm{S}-100 \mathrm{~b}$ protein also resulted in an increase of sensitivity from 97 to $100 \%$. The combination of 14-3-3 protein with t-tau or $\mathrm{p}$-tau/t-tau ratio failed to correctly allocate two non-CJD patients (a 41-year-old male with an encephalopathy and a 58-year-old female with vascular dementia) and one sCJD patient (the 47-year-old female, with a long disease duration, previously mentioned). Combining 14-3-3 protein with $\mathrm{S}-100 \mathrm{~b}$ failed only to correctly diagnose a 51-year-old male, with a fronto-temporal dementia evolving over a 18 months period. Combination of $\mathrm{S}-100 \mathrm{~b}$ with the other quantitative protein markers also improved accuracy, with the association with t-tau correctly allocating all non-CJD cases and only failing to allocate one sCJD patient (a 69-year-old male, with a 2 months duration dementia). Associating S-100b with either $\mathrm{t}$-tau/A $\beta 42$ or $\mathrm{p}$-tau181/t-tau ratios showed to be particularly advantageous, resulting in a correct allocation of $100 \%$ of the cases.

Influence of age and disease duration on protein markers

Next we have analysed the influence of age and disease duration at the time of sampling in the different protein markers assessed. For that we divided the patients in two groups, either according to age ( $<60$ and $\geq 60$ years) or disease duration ( $<12$ and $\geq 12$ months). In sCJD patients, a CSF 14-3-3 protein positive test was more frequently associated with older patients and shorter disease duration (Table 4). Regarding quantitative markers, patients age did not influence the levels of CSF A $\beta 42$ or S-100b levels, but appeared to influence the levels of t-tau and p-tau181, with younger sCJD patients presenting with a trend for lower t-tau $(<60$ years $=6,291 \pm 2,169 \mathrm{pg} / \mathrm{mL} ; \quad \geq 60$ years $=$ $13,366 \pm 2,719 \mathrm{pg} / \mathrm{mL} ; P>0.05)$ and higher $\mathrm{p}$-tau181 levels $\quad(<60$ years $=43.4 \pm 7.8 \mathrm{pg} / \mathrm{mL} ; \quad \geq 60$ years $=$
Table 4 Findings for the protein markers tested according to age, duration of illness, PRNP codon 129 genotype, PrP type and molecular subtype in SCJD patients

Classical subtype: MM1 and MV1; non-classical subtype: MV2, VV1 and VV2

14-3-3 +: all bands considered; t-tau $+:>1203 \mathrm{pg} / \mathrm{mL}: \mathrm{S} 100 \mathrm{~b}$

$+:>2.59 \mathrm{pg} / \mathrm{mL}$

t-tau/A $\beta 42+:>5.83$; p-tau/t-tau

$+:>1.66$

$* P<0.05$ versus age $<60$ years; ${ }^{\delta} P<0.05$ versus duration $\geq 12$ months; ${ }^{\#} P<0.05$ versus $P R N P$ genotype $\mathrm{MM} ;{ }^{\xi} P<0.05$ versus PrP-type 1

\begin{tabular}{|c|c|c|c|c|c|}
\hline & $\begin{array}{l}14-3-3 \\
+/ \text { total }(\%)\end{array}$ & $\begin{array}{l}\text { t-tau } \\
+/ \text { total }(\%)\end{array}$ & $\begin{array}{l}\text { S100b } \\
\text { +/total }(\%)\end{array}$ & $\begin{array}{l}\text { t-tau/A } \beta 42 \\
\text { +/total }(\%)\end{array}$ & $\begin{array}{l}\text { p-tau/tau } \\
+/ \text { total }(\%)\end{array}$ \\
\hline \multicolumn{6}{|l|}{ Age (years) } \\
\hline$<60$ & $4 / 5(80)$ & $4 / 5(80)$ & $5 / 5(100)$ & $4 / 5(80)$ & $3 / 5(60)$ \\
\hline$\geq 60$ & $25 / 25(100)^{*}$ & $23 / 25(92)$ & $23 / 25(92)$ & $24 / 25(96)$ & $25 / 25(100)^{*}$ \\
\hline \multicolumn{6}{|c|}{ Duration (months) } \\
\hline$<12$ & 27/27 (100) & 25/27 (93) & 25/27 (93) & 26/27 (96) & 27/27 (100) \\
\hline$\geq 12$ & $2 / 3(67)^{\delta}$ & $2 / 3(67)$ & $3 / 3(100)$ & $2 / 3(67)$ & $1 / 3(33)^{\delta}$ \\
\hline \multicolumn{6}{|l|}{ PRNP } \\
\hline MM & 18/18 (100) & $17 / 18(94)$ & $16 / 18(89)$ & 18/18 (100) & 18/18 (100) \\
\hline MV & $5 / 6(83)$ & $4 / 6(67)$ & $6 / 6(100)$ & $4 / 6(67)^{\#}$ & $4 / 6(67)^{\#}$ \\
\hline VV & 4/4 (100) & 4/4 (100) & 4/4 (100) & 4/4 (100) & $4 / 4(100)$ \\
\hline \multicolumn{6}{|l|}{ PrP type } \\
\hline 1 & 13/13 (100) & $11 / 13(85)$ & $12 / 13(92)$ & $12 / 13(92)$ & 13/13 (100) \\
\hline $2 \mathrm{~A}$ & $2 / 3(67)^{\xi}$ & $2 / 3(67)$ & $3 / 3(100)$ & $2 / 3(67)$ & $2 / 3(67)^{\xi}$ \\
\hline \multicolumn{6}{|l|}{ Subtype } \\
\hline Classical & 11/11 (100) & 9/11 (82) & $10 / 11(91)$ & $10 / 11(91)$ & 11/11 (100) \\
\hline Non-classical & $3 / 4(75)$ & $3 / 4(75)$ & 4/4 (100) & $3 / 4(75)$ & $3 / 4(75)$ \\
\hline \multicolumn{6}{|l|}{ Subtype } \\
\hline MM1 & 7/7 (100) & $6 / 7(86)$ & $6 / 7(86)$ & $7 / 7(100)$ & $7 / 7(100)$ \\
\hline MV1 + MV2 & $4 / 5(80)$ & $3 / 5(60)$ & $5 / 5(100)$ & $3 / 5(60)$ & $4 / 5(80)$ \\
\hline VV1 + VV2 & $3 / 3(100)$ & $3 / 3(100)$ & $3 / 3(100)$ & $3 / 3(100)$ & $3 / 3(100)$ \\
\hline
\end{tabular}


$35.8 \pm 4.5 \mathrm{pg} / \mathrm{mL} ; P>0.05)$, resulting in a significantly higher p-tau181/t-tau ratio $(<60$ years $=1.80 \pm 1.04$; $\geq 60$ years $=0.45 \pm 0.07 ; \quad P<0.05)$. Likewise, sCJD patients with a longer duration of disease showed a trend for higher p-tau181 levels $(<12$ months $=35.6 \pm 4.2 \mathrm{pg}$ / $\mathrm{mL} ; \geq 12$ months $=50.2 \pm 13.8 \mathrm{pg} / \mathrm{mL} ; P>0.05)$ and $\mathrm{a}$ significantly higher $\mathrm{p}$-tau $181 / \mathrm{t}$-tau ratio $(<12$ months $=$ $0.46 \pm 0.07 ; \geq 12$ months $=2.61 \pm 1.68 ; P<0.05)$. In accordance to these data, a p-tau181/t-tau ratio positive result (i.e. <1.66) was less likely in younger patients and longer disease duration (Table 4). Age and duration of disease did not influence the levels of any of the protein markers in the non-CJD group (data not-shown).

\section{Influence of ApoE and PRNP genotypes on protein} markers

We looked for an influence of the ApoE genotype on the levels of the protein markers assessed (data not shown). This analysis is obviously limited by the very low frequency of some of the genotypes, and the only significant association found was between the presence of an $\varepsilon 2$ allele and higher CSF A $\beta 42$ levels in SCJD patients (with $\varepsilon 2$ allele $=727.1 \pm 117.1 \mathrm{pg} / \mathrm{mL}$; without $\varepsilon 2$ allele $=$ $382.7 \pm 72.7 \mathrm{pg} / \mathrm{mL} ; P<0.05)$.

In the sCJD group we also examined the influence of PRNP codon 129 polymorphism, PrP-type and molecular subtype on the sensitivity of the different markers. A positive 14-3-3 result was found in all homozygotes (MM and VV) or PrP-type1 patients, while the sensitivity of this test was lower for the MV genotype and even lower for PrP-type $2 \mathrm{~A}$ subtype (Table 4). CSF levels of A $\beta 42$, t-tau and $\mathrm{S}-100 \mathrm{~b}$ seemed not to be influenced by any of these characteristics (not shown). However, significantly lower p-tau181 levels were associated with PrP-type1 patients (PrP-type $1=32.9 \pm 4.7 \mathrm{pg} / \mathrm{mL}$; PrP-type $2 \mathrm{~A}=69.2 \pm$ $8.2 \mathrm{pg} / \mathrm{mL} ; P<0.05)$. Accordingly, a significant decrease of p-tau181/t-tau ratio was also found in PrP-type 1 patients (PrP-type $1=0.51 \pm 0.08 ;$ PrP-type $2 \mathrm{~A}=2.65 \pm 1.62$; $P<0.05)$. In this subgroup of sCJD, all patients had a positive p-tau181/t-tau ratio result, whereas only $67 \%$ of PrP-type2 or heterozygotes (MV) tested positive for this parameter $(P<0.05$; Table 4$)$. The sensitivity of the t-tau/ A $\beta 42$ test was also lower in $\mathrm{MV}$ patients $(P<0.05$; Table 4).

Due to the reduced number of patients for whom both PRNP codon 129 polymorphism and PrP-type were available, we initially chose to consider only two different molecular subtypes: classical (including MM1 and MV1 cases) and non-classical (including MV2 and all VV cases). Both 14-3-3 and p-tau181/t-tau ratio seemed less sensitive for the non-classical subtype, but the difference failed to reach statistical significance (Table 4). Significantly lower p-tau181 levels were associated with the classical molecular subtype (classical $=32.9 \pm 5.6 \mathrm{pg} / \mathrm{mL}$; non-classical $=60.6 \pm 10.4 \mathrm{pg} / \mathrm{mL} ; P<0.05)$. Since cases of sCJD show co-occurrence of type 1 and type $2 \mathrm{PrP}$ in the brain [35], and knowing that codon 129 genotype influences the course of the disease, we have re-analysed the influence of molecular subtype considering three different subtypes: MM1; MV1 + MV2A and VV1 + VV2A. Although no statistical significant differences were seen for any of the protein markers tested (Table 4 ), there was a trend for 14-3-3, t-tau, t-tau/A $\beta 42$ ratio and $\mathrm{p}$-tau $181 / \mathrm{t}$-tau ratio sensitivity to be lower for the MV1 + MV2A subgroup.

\section{Discussion}

In this work, performed under the scope of the Portuguese Surveillance Network for Human Prion Diseases, we report the results of a prospective study on biochemical markers for sCJD. We assessed the value of 14-3-3 protein and other protein markers in CSF, A $\beta 42$, t-tau, p-tau 181 and $\mathrm{S}-100 \mathrm{~b}$, as tools for the differential diagnosis of sCJD. Our study group consisted of 30 definite sCJD patients, presenting with a rapidly progressive dementia, associated in most cases with myoclonus and ataxia. The control group enrolled 41 age-matched patients, with a clinical suspicion of sCJD, but in whom an alternative diagnosis was reached (non-CJD). All non-CJD patients presented with dementia, and in most cases another symptom, most often psychiatric problems, could be found.

Regarding the molecular characteristics of the sCJD group, the frequency of the various PRNP genotypes was broadly in accordance with the frequency distributions generally reported in the literature $[9,24]$. Also as expected [9, 24], most patients had a type-1 PrP isoform, and MM1 molecular subtype was the most frequent. There was however, a fairly strong representation of the less frequent MV1 subtype and one patient with the very rare VV1 subtype. The rare MM2 subtype was absent from our population. ApoE genotyping was performed in a subset of the population, showing no differences in the distribution of the different genotypes between the two diagnostic groups. However, a statistically lower frequency of the ApoE- $\varepsilon 4$ allele was found in the sCJD group. This difference could, at least in part, be accounted by the fact that our control group consisted of a population with a large proportion of patients with other types of dementia, including five patients with Alzheimer's disease, for which the ApoE- $\varepsilon 4$ allele is a well known risk factor. In fact, the frequency of the ApoE- $\varepsilon 4$ allele for the sCJD group (12\%) is very similar to that we have found in the healthy Portuguese population (10\%) (unpublished data), and also reported by others [20]. Contradictory results exist in the 
literature regarding the frequency and association of the ApoE genotype with sCJD. While some authors consider that there is no association between ApoE genotype and SCJD [20, 31, 44], others postulate that ApoE- $\varepsilon 4$ allele is an independent risk factor for SCJD [1,37]. The discrepancy between our results and those stated above, can be due to the different control populations considered (other neurological condition with a clinical suspicion of SCJD vs. healthy subjects), and also to regional differences in the frequency of the ApoE genotypes [3, 23]. However, the trend for the $\varepsilon 2$-allele to be associated with older SCJD patients and with longer disease duration is in line with evidence showing that this allele can delay the occurrence of death in CJD patients [1].

From the commonly employed routine investigations for the diagnosis of sCJD (EEG, CSF analysis and MRI), CSF 14-3-3 protein immunodetection was the most sensitive ( $97 \%$ vs. $63 \%$ for EEG and $40 \%$ for MRI). This is in agreement with recent data from an international collaborative study [9], and with the majority of the literature reporting the sensitivity of the 14-3-3 test [22, 30, 37, 39]. However, the specificity of the 14-3-3 assay, in our population, was clearly sub optimal (78\%), lower than the EEG $(86 \%)$ and that reported in most previous studies [22, 30, $37,39]$. The poor specificity of the 14-3-3 assay, already noted in some studies $[6,7]$, is probably related to the wide range of pathologies included in our control population that can lead to rapid and massive neuronal destruction. Therefore, our results suggest that CSF protein 14-3-3 determination should not be used as a screening test for sCJD. Another explanation for our low specificity can be related to individual differences in evaluation of the presence of 14-3-3 and with the definition of positive bands. There is no standard approach to this matter, with some authors considering all bands [22], while others only considering strong bands as positive [30]. In fact, re-analysing our data, considering only strong 14-3-3 bands as positive, increases specificity to $100 \%$, with sensitivity decreasing to $87 \%$. To avoid person-to-person bias of visual inspection and the difficult interpretation of weak bands, a densitometric analysis of the 14-3-3 immunoblots has been performed [39]. The method resulted in an increase in specificity but also in a decrease of the sensitivity compared to the visual analysis. Other studies have compared the western blot analysis with different enzyme linked immunoassays (ELISAs), resulting in a similar specificity but also a lower sensitivity $[13,18]$. The difficulty of standardization of the 14-3-3 immunoassay reinforces the need for other protein markers.

From the different protein markers we have tested, and as had been previously reported [17, 38, 39], A $\beta 42$ and p-tau alone do not seem suitable to be used as diagnostic markers for SCJD, as their levels largely overlap with those found in the non-CJD group. The extremely high levels of $\mathrm{t}$-tau that we found in SCJD patients are in accordance with other studies [5, 14, 22, 28, 32, 38, 39], with sensitivity $(87-94 \%)$ and specificity (90-100\%) figures similar to ours. In fact, t-tau has been suggested to be the most sensitive marker in early stage sCJD [33]. The association of $\mathrm{t}$-tau and $\mathrm{A} \beta 42$ (t-tau/A $\beta 42$ ratio) resulted in slight improvement in both sensitivity (from $90 \%$ to $93 \%$ ) and specificity (form $95 \%$ to $98 \%$ ). Furthermore, associating ttau with p-tau (p-tau/t-tau ratio) improved the sensitivity of the t-tau test alone (from $90 \%$ to $93 \%$ ), but not its specificity $(95 \%)$. This is in line with previous studies, reporting comparable sensitivity (78-100\%) and specificity (93$100 \%)[2,5,28,32]$. The increase in CSF S-100b levels observed in SCJD patients has been previously reported, but the absolute values are difficult to compare as different methodologies have been employed [14, 30, 31]. Using a commercial ELISA test for S-100b, we have reached a sensitivity and specificity of $93 \%$, both higher than those reported using either an in-house ELISA or a different commercial kit [21, 30, 43]. We tried to establish quantitative correlations between the different biochemical parameters and found positive correlations between the levels of three proteins: t-tau, p-tau and S-100b in SCJD patients, probably reflecting a relation between neuronal damage and astrocytic gliosis.

Dividing sCJD patients according to age $(<60$ and $\geq 60$ years) and disease duration $(<12$ and $\geq 12$ months), we found that these features influenced the sensitivity of the 14-3-3 immunoassay and of the p-tau/t-tau ratio, but not of the t-tau or S-100b test. Contradictory results exist regarding this issue. Although disease duration clearly seems to affect 14-3-3 sensitivity, the influence of age is not so widely accepted [9, 30, 39]. As for t-tau and S-100b, earlier studies failed to find any influence of age and/or disease duration on these protein markers sensitivity $[17,39]$, but a more recent study, conducted in a large population of CJD patients, succeeded in doing so [30].

Other factors known to influence the sensitivity of CSF protein 14-3-3 testing are PRNP codon 129 polymorphism and PrP-isotype. In our work, all PrP-type 1 and homozygotes for PRNP 129 polymorphism had a positive 14-3-3, whereas two out of three PrP-type 2A and five out of six MV cases, had a positive signal. This difference failed to reach statistical significance, probably due to the limited number of MV and PrP-type 2A patients, but is in agreement with the findings of large collaborative studies $[9,30]$. In relation to the other protein markers, t-tau and $\mathrm{S}-100 \mathrm{~b}$ have also reported higher sensitivity for MM or VV than for MV patients, and also for PrP-type 1 patients [30]. There was a trend for such a difference for t-tau test in our study, with $96 \%$ of homozygotes and $85 \%$ of PrP-type 1 patients testing positive, but only $67 \%$ of MV or PrP-type 2 
cases having a positive $\mathrm{t}$-tau value. In relation to these molecular characteristics, we could find statistical significant differences in sensitivity for the t-tau/A $\beta 42$ (lower for $\mathrm{MV}$ ) and for $\mathrm{p}$-tau/t-tau test (lower for MV and PrP-type $2 \mathrm{~A}$ cases). In our hands, S-100b seemed largely independent of all these molecular characteristics, showing a high sensitivity for all subgroups of patients and was the only marker that could positively identify the atypical SCJD case that had a negative 14-3-3. Regarding the influence of the molecular subtype on protein markers sensitivity, and comparing the different approaches that we have used, we can see that considering three different subtypes (MM1, MV1 + MV2A, VV1 + VV2A) has similar results than dividing the patients in relation only to PRNP codon 129 polymorphism. Therefore, it seems that PRNP polymorphism has a stronger influence than PrP-type on markers sensitivity, which is in agreement with the co-occurrence of type 1 and type $2 \operatorname{PrP}$ in the brain of sCJD patients [35]. This seems to argue against the conventional classification of molecular subtypes into classical and non-classical, and might be of relevance to patients diagnosis, since PRNP polymorphism is the only characteristic that can be determined during the patient life.

Overall, 14-3-3 and p-tau/t-tau ratio were the markers most influenced by the patients characteristics, with a sensitivity higher for older patients $(>60)$, short disease duration ( $<12$ months), homozygotes for PRNP codon 129 and PrP-type 1. Despite the fact that the relatively small number of patients might limit the conclusions taken from this analysis, these are in general agreement with the results from large population studies $[9,30]$. This difference in the protein markers sensitivity between SCJD subtypes might be accounted by the modulation of clinical phenotype by molecular characteristics. A host genotype effect has been reported, with codon 129 heterozygosity increasing the duration of illness, [15] and prion strain influencing disease onset [9]. In fact, in our study, there was a trend for MV and PrP-type 2A patients to be younger and with a longer disease course (data not shown). Therefore, patients with an early disease onset and a less rapidly progressive disease course would present with less age-dependent neuronal vulnerability and less acute neuronal damage [25], leading to a less pronounced release of brain-derived proteins into the CSF. This is in agreement with the fact that, in our hands, S-100b, a protein that reflects astrocytic gliosis was the only marker independent of patients molecular characteristics, while 14-3-3, t-tau and p-tau, that reflect neuronal damage, were all influenced by codon 129 genotype and PrP-type.

Comparing with a single marker, the combination of tests (14-3-3 with either elevated levels of t-tau or S-100b, or combining $\mathrm{S}-100 \mathrm{~b}$ test with the ratios of two other proteins- $\mathrm{t}$-tau/A $\beta 42$ or $\mathrm{p}$-tau/t-tau) clearly improved the sensitivity and specificity to optimal levels. We, therefore, propose that, besides from 14-3-3 protein, a second CSF protein marker should be used in clinical practice for SCJD diagnosis. This would be specially advised in cases where 14-3-3 gives a weak positive result, or in cases with an atypical presentation, like younger patients with long disease duration and/or heterozygotes for the PRNP codon 129.

Acknowledgments The authors thank the Portuguese Surveillance Group for Human Prion Diseases, its coordinator and José Cortez Pimentel (Hospital de Sta. Maria, Lisbon) for support and implementation of the study. We are grateful to Alison Green (National CJD Surveillance Unit, University of Edinburgh) for scientific advice, Manuela Grazina, Filipe Silva (Department of Biochemistry, Faculty of Medicine, Universidade de Coimbra), Pedro Loureiro and Conceição Silva (Genetics Department, National Institute of Health Dr. Ricardo Jorge, Lisbon) for technical assistance and Gil Cunha (Center for Neuroscience and Cell Biology, PDBEB, University of Coimbra) for reviewing the MRI reports. We also wish to thank all the physicians who sent us the CSF and brain samples and clinical and neuropathological information on suspected CJD cases: Isabel Santana (Hospitais da Universidade de Coimbra), Álvaro Machado (Hospital de S. Marcos, Braga), Grilo Gonçalves (Centro Hospitalar de Coimbra), Miguel Veloso (Hospital de S. Miguel, Oliveira de Azeméis), Edmeia Monteiro (Hospital do Barlavento Algarvio, Portimão), Alfredo de Sá (Hospital S. André, Leiria) Carolina Garrett (Hosp S. João, Porto) Dílio Alves (Hospital Pedro Hispano, Matosinhos) José Pimentel (Hospital Sta. Maria, Lisbon) Isabel Carmo (Hospital Egas Moniz, Lisbon), Rita Almeida (Hospital S. António dos Capuchos, Lisbon), Bastos Lima (Hospital S. António, Porto), Joaquim Machado Cândido (Hosp S. José, Lisbon) Elia Baeta (Centro Hospitalar Alto Minho, Viana do Castelo) and Miguel Viana Baptista (Hospital Garcia de Orta, Lisbon).

\section{References}

1. Amouyel P, Vidal O, Launay JM, Laplanche JL (1994) The apolipoprotein E alleles as major susceptibility factors for Creutzfeldt-Jakob disease. The French Research Group on Epidemiology of Human Spongiform Encephalopathies. Lancet 344:1315-1318. doi:10.1016/S0140-6736(94)90691-2

2. Blennow K, Johansson A, Zetterberg H (2005) Diagnostic value of 14-3-3 $\beta$ immunoblot and T-tau/P-tau ratio in clinically suspected Cretzfeldt-Jakob disease. Int J Mol Med 16:1147-1149

3. Bosco P, Guéant-Rodriguez RM, Anello G, Spada RS, Romano A, Caraci F, Ferri R, Guéant JL (2005) Allele epsilon 4 of ApoE is a stronger predictor of Alzheimer risk in Sicily than in continental South Italy. Neurosci Lett 388:168-172

4. Budka H, Aguzzi A, Brown P, Brucher JM, Bugiani O, Gullotta F, Haltia M, Hauw JJ, Ironside JW, Kl Jellinger (1995) Neuropathological diagnostic criteria for Creutzfeldt-Jakob disease (CJD) and other human spongiform encephalopathies (prion diseases). Brain Pathol 5:459-466. doi:10.1111/j.1750-3639. 1995.tb00625.x

5. Buerger K, Otto M, Teiperl SJ, Zinkowski R, Blennow K, DeBernardis J, Kerkman D, Schröeder J, Schönknecht P, Cepek L, McCulloch C, Möller HJ, Wiltfang J, Kretzschmar H, Hampel H (2006) Dissociation between CSF total tau and tau protein phosphorylated at threonine 231 in Creutzfeldt-Jakob disease. Neurobiol Aging 27:10-15. doi:10.1016/j.neurobiolaging.2004. 12.003 
6. Burkhard PR, Sanchez JC, Landis T, Hochstrasser DF (2001) CSF detection of the 14-3-3 protein in unselected patients with dementia. Neurology 56:1528-1533

7. Chapman T, McKeel DW Jr, Morris JC (2000) Misleading results with the 14-3-3 assay for the diagnosis of Creutzfeldt-Jakob disease. Neurology 55:1396-1397

8. Collie DA, Sellar RJ, Zeidler M, Colchester AC, Knight R, Will RG (2001) MRI of Creutzfeldt-Jakob disease: imaging features and recommended MRI protocol. Clin Radiol 56:726-739. doi: 10.1053/crad.2001.0771

9. Collins SJ, Sanchez-Juan P, Masters CL, Klug GM, van Duijn C, Poleggi A, Pocchiari M, Almonti S, Cuadrado-Corrales N, de Pedro-Cuesta J, Budka H, Gelpi E, Glatzel M, Tolnay M, Hewer E, Zerr I, Heinemann U, Kretszchmar HA, Jansen GH, Olsen E, Mitrova E, Alpérovitch A, Brandel JP, Mackenzie J, Murray K, Will RG (2006) Determinants of diagnostic investigation sensitivities across the clinical spectrum of sporadic Creutzfeldt-Jakob disease. Brain 129:2278-2287. doi:10.1093/brain/awl159

10. Crook R, Hardy J, Duff K (1994) Single-day apolipoprotein E genotyping. J Neurosci Methods 53:125-127. doi:10.1016/01650270(94)90168-6

11. Geschwind MD, Martindale J, Miller D, DeArmond SJ, UyeharaLock J, Gaskin D, Kramer JH, Barbaro NM, Miller BL (2003) Challenging the clinical utility of the 14-3-3 protein for the diagnosis of sporadic Creutzfeldt-Jakob disease. Arch Neurol 60:813-816. doi:10.1001/archneur.60.6.813

12. Goodall CA, Head MW, Everington D, Ironside JW, Knight RSG, Green AJE (2006) Raised CSF phospho-tau concentrations in variant Creutzfeldt-Jakob disease: diagnostic and pathological implications. J Neurol Neurosurg Psychiatry 77:89-91. doi: 10.1136/jnnp.2005.065755

13. Green AJ, Ramljak S, Muller WE, Knoght RS, Schroeder HC (2002) 14-3-3 in the cerebrospinal fluid of patients with variant and sporadic Creutzfeldt-Jakob disease measured using a capture assay able to detect low levels of 14-3-3 protein. Neurosci Lett 324:57-60. doi:10.1016/S0304-3940(02)00172-6

14. Green AJ, Thompson EJ, Stewart GE, Zeidler M, McKenzie JM, MacLeod MA, Ironside JW, Will JG, Knight RS (2001) Use of 14-3-3 and other brain-specific proteins in CSF in the diagnosis of variant Creutzfeldt-Jakob disease. J Neurol Neurosurg Psychiatry 70:744-748. doi:10.1136/jnnp.70.6.744

15. Hill AF, Joiner S, Wadsworth JDF, Sidle KCL, Bell JE, Budka H, Ironside JW, Collinge J (2003) Molecular classification of sporadic Creutzfeldt-Jakob disease. Brain 126:1333-1346. doi: 10.1093/brain/awg 125

16. Ironside JW, Head MW, Bell JE, McCardle L, Will RG (2000) Laboratory diagnosis of variant Creutzfeldt-Jakob disease. Histopathology 37:1-9. doi:10.1046/j.1365-2559.2000.00946.x

17. Kapaki E, Kilidireas K, Paraskevas GP, Michalopoulou M, Patsouris E (2001) Highly increased CSF tau protein and decreased $\beta$-amyloid (1-42) in sporadic CJD: a discrimination from Alzheimer's disease? J Neurol Neurosurg Psychiatry 71:401-403. doi:10.1136/jnnp.71.3.401

18. Kenney K, Brechtel C, Takahashi H, Kurohara K, Anderson P, Gibbs CJ Jr (2000) An enzyme-linked immunosorbent assay to quantify 143-3 proteins in the cerebrospinal fluid of suspected Creutzfeldt-Jakob disease. Ann Neurol 48:395-398. doi:10.1002/1531-8249(200009) 48:3<395::AID-ANA18>3.0.CO;2-A

19. Lemstra AW, van Meegen MT, Vreyling JP, Meijering PH, Jansen GH, Bulk S, Baas F, van Gool WA (2000) 14-3-3 testing in diagnosing Creutzfeldt-Jakob disease: a prospective study in 112 patients. Neurology 55:514-516

20. Nakagawa Y, Kitamoto T, Furukawa H, Ogomori K, Tateishi J (1995) Alelic variatic of apolipoprotein E in Japanese sporadic Creutzfeldt-Jakob disease patients. Neurosci Lett 187:209-211. doi:10.1016/0304-3940(95)11366-5
21. Otto M, Stein H, Szudra A, Zerr I, Bodemer M, Gefeller O, Poser S, Kretzschmar HA, Mäder M, Weber T (1997) S-100 protein concentration in the cerebrospinal fluid of patients with Creutzfeldt-Jakob disease. J Neurol 244:566-570. doi:10.1007/s00415 0050145

22. Otto M, Wiltfang J, Cepek L, Neumann M, Mollenhauer B, Steinacker P, Ciesielczyk B, Schulz-Schaeffer W, Kretzschmar HA, Poser S (2002) Tau protein and 14-3-3 protein in the differential diagnosis of Creutzfeldt-Jakob disease. Neurology 58:192-197

23. Panza F, Díntrono A, Colacicco AM, Capruso C, Basile AM, Capurso S, Capurso A, Solfrizzi V (2004) Regional European differences in allele and genotype frequencies of low density lipoprotein receptor-related protein 1 polymorphism in Alzheimer's disease. Am J Med Genet B Neuropsychiatr Genet 126:6973. doi:10.1002/ajmg.b.20146

24. Parchi P, Giese A, Capellari S, Brown P, Schulz-Schaeffer W, Windl O, Zerr I, Budka H, Kopp N, Piccardo P, Poser S, Rojiani A, Streichemberger N, Julien J, Vital C, Ghetti B, Gambetti P, Kretzschmar H (1999) Classification of sporadic CreutzfeldtJakob disease based on molecular and phenotypic analysis of 300 patients. Ann Neurol 46:224-233. doi:10.1002/1531-8249 (199908)46:2<224::AID-ANA12>3.0.CO;2-W

25. Pocchiari M, Poupolo M, Croes EA, Budka H, Gelpi E, Collins S, Lewis V, Sutcliffe T, Guilivi A, Delasnerie-Laupretre N, Brandel JP, Alperovitch A, Zerr I, Poser S, Kretzschmar HA, Ladogana A, Rietvald I, Mitrova E, Martinez-Martin P, de Pedro-Cuesta J, Glatzel M, Aguzzi A, Cooper S, Mackenzie J, van Duijn CM, Will RG (2004) Predictors of survival in sporadic Creutzfeldt-Jakob disease and other human transmissible spongiform encephalopathies. Brain 127:2348-2359. doi:10.1093/brain/awh249

26. Poser S, Mollenhauer B, Kraubeta A, Zerr I, Steinhoff BJ, Schroeter A, Finkenstaedt M, Schulz-Schaeffer WJ, Kretzschmar HA, Felgenhauer K (1999) How to improve the clinical diagnosis of Creutzfeldt-Jakob disease. Brain 12:2345-2351. doi:10.1093/ brain/122.12.2345

27. Prusiner SB, Hsiao KK (1994) Human prion diseases. Ann Neurol 35:385-395. doi:10.1002/ana.410350404

28. Riemenschneider M, Wagenpfeil S, Vanderstichele H, Otto M, Wiltfang J, Kretzschmar H, Vanmechelen E, Förstl H, Kurz A (2003) Phospho-tau/total tau ratio in cerebrospinal fluid discriminates Creutzfeldt-Jakob disease from other dementias. Mol Psychiatry 8:343-347. doi:10.1038/sj.mp.4001220

29. Salvatore M, Seeber AC, Nacmias B, Petraroli R, Dálessandro M, Sorbi S, Pocchiari M (1995) Apolipoprotein E in sporadic and familial Creutzfekdt-Jakob disease. Neurosci Lett 199:95-98. doi:10.1016/0304-3940(95)12030-8

30. Sanchez-Juan P, Green A, Ladogana A, Cuadrado-Corrales N, Sáanchez-Valle R, Mitrováa E, Stoeck K, Sklaviadis T, Kulczycki J, Hess K, Bodemer M, Slivarichová D, Saiz A, Calero M, Ingrosso L, Knight R, Janssens AC, van Duijn CM, Zerr I (2006) CSF tests in the differential diagnosis of Creutzfeldt-Jakob disease. Neurology 67:637-643. doi:10.1212/01.wnl.0000 230159.67128.00

31. Sanchez-Juan P, Sanchez-Valle R, Green A, Ladogana A, Cuadrado-Corrales N, Mitrová E, Stoeck K, Sklaviadis T, Kulczycki J, Hess K, Krasnianski A, Equestre M, Slivarichová D, Saiz A, Calero M, Pocchiari M, Knight R, van Dujin C, Zerr I (2007) Influence of timing on CSF tests value for Cretzfeldt-Jakob disease diagnosis. J Neurol 254:901-906. doi:10.1007/s00415-006-0472-9

32. Satoh K, Shirabe S, Eguchi H, Tsujino A, Eguchi K, Satoh A, Tsujihata M, Niwa M, Katamine S, Kurihara S, Matsuo H (1995) 14-3-3 protein, total tau and phosphorylated tau in cerebrospinal fluid of patients with Creutzfeldt-Jakob disease and neurodegenerative disease in Japan. Cell Mol Neurobiol 26:45-52. doi: 10.1007/s10571-006-9370-z 
33. Satoh K, Shirabe S, Tsujino A, Eguchi H, Motomura M, Honda H, Tomita I, Satoh A, Tsujihata M, Matsuo H, Nakagawa M, Eguchi K (2007) Total tau protein in cerebrospinal fluid and diffusion-weighted MRI as an early diagnostic marker for Creutzfeldt-Jakob disease. Dement Geriatr Cogn Disord 24:207-212. doi: $10.1159 / 000107082$

34. Steinhoff BJ, Zerr I, Glatting M, Schulz-Schaeffer W, Poser S, Kretzschmar HA (2004) Diagnostic value of periodic complexes in Creutzfeldt-Jakob disease. Ann Neurol 56:702-708. doi: 10.1002/ana.20261

35. Uro-Coste E, Cassard H, Simon S, Lugan S, Bilheude JM, PerretLiaudet A, Ironside JW, Haik S, Basset-Leobon C, Lacroux C, Peoch K, Streichenberger N, Langeveld J, Head MW, Grassi J, Hauw JJ, Schelcher F, Delisle MB, Andréoletti O (2008) Beyond PrPres type 1/type 2 dichotomy in Creutzfeldt-Jakob disease. PLoS Pathog 4:e1000029. doi:10.1371/journal.ppat.1000029

36. Van Everbroeck B, Boons J, Cras P (2005) Cerebrospinal fluid biomarkers in Creutzfeldt-Jakob disease. Clin Neurol Neurosurg 107:355-360. doi:10.1016/j.clineuro.2004.12.002

37. Van Everbroeck B, Croses EA, Pals P, Dermaut B, Jansen G, van Dujin CM, Cruts M, van Broeckhoven C, Martin JJ, Cras P (2001) Influence of the prion protein and the apolipoprotein $\mathrm{E}$ genotype on the Creutzfelt-Jakob disease phenotype. Neurosci Lett 313:69-72. doi:10.1016/S0304-3940(01)02264-9

38. Van Everbroeck B, Green AJE, Vanmechelen E, Vanderstichele H, Pals P, Sanchez-Valle R, Cuadrado Corrales N, Martin JJ, Cras
P (2002) Phosphorylated tau in cerebrospinal fluid as a marker for Creutzfeldt-Jakob disease. J Neurol Neurosurg Psychiatry 73:7982. doi:10.1136/jnnp.73.1.79

39. Van Everbroeck B, Quoilin S, Boons J, Martin JJ, Cras P (2003) A prospective study of CSF markers in 250 patients with possible Creutzfeldt-Jakob disease. J Neurol Neurosurg Psychiatry 74:1210-1214. doi:10.1136/jnnp.74.9.1210

40. Weber T (2000) Clinical and laboratory diagnosis of CreutzfeldtJakob disease. Clin Neuropathol 19:249-250

41. World Health Organization. Report of a WHO consultation on global surveillance, diagnosis and therapy of human transmissible spongiform encephalopathies. WHO, Geneva, 8-11 February 1998

42. Zerr I, Bodemer M, Gefeller O, Otto M, Poser S, Wiltfang J, Windl O, Kretzschmar HA, Weber T (1998) Detection of 14-3-3 protein in the cerebrospinal fluid supports the diagnosis of Creutzfeldt-Jakob disease. Ann Neurol 43:32-40. doi:10.1002/ana. 410430109

43. Zerr I, Bodemer M, Räcker S, Grosche S, Poser S, Kretzschmar HA, Weber T (1995) Cerebrospinal fluid concentration of neuronspecific enolase in diagnosis of Creutzfeldt-Jakob disease. Lancet 345:1609-1610. doi:10.1016/S0140-6736(95)90118-3

44. Zerr I, Helmhold M, Poser S, Armstrong VW, Weber T (1996) Apolipoprotein $\mathrm{E}$ phenotype frequency and cerebrospinal fluid concentration are not associated with Creutzfeldt-Jakob disease. Arch Neurol 53:1233-1238 